\title{
The great divide: From viscometer to vasculature
}

\author{
Lecture held during the 14th European Conference for Clinical Hemorheology and \\ Microcirculation, Dresden, Germany
}

\author{
Michael W. Ramping \\ School of Medicine, Imperial College, South Kensington, London SW7 2AZ, UK
}

\section{Introduction}

It is traditional at the Fåhraeus Award Ceremony for the previous winner to give the laudatio to the new one. This meant that my dear friend, Michel Boisseau, should have given it this year but, for personal reasons, he was unable to attend the meeting. This was sad but we all wished him well. However, it is an ill wind. . . and the result was that I was twice blessed in having a double laudatio, from my very old friends Dirk Seiffge and Herb Meiselman and I thank them both for their kindness.

When I heard from Professor Jung that I had won the Medal I was, of course, extremely moved. I spent the bulk of my active research life involved in the field of haemorheology. It has given me immense pleasure over those years and allowed me to meet and make friends with some of the finest people that I know. It is an enormous honour, in the early stages of my retirement, to be recognised by my peer group and awarded the Medal so that I can join the previous winners (Table 1) all of whose work I greatly respect and many of whom I class as good friends. I am deeply grateful to all who have participated in honouring me this way. My only worry is that I am number thirteen; I just hope that that is not portentous!

Now to the lecture; as I am recently retired from active research this is likely to be the last time that I shall write up a serious lecture given to my haemorheological friends. So I intend too indulge myself, to reminisce a little and to ride one or two of my haemorheological hobby-horses.

\section{Early career}

I started my professional life in 1961 after leaving Imperial College in London with a degree in Physics. My first post was with the United Kingdom Atomic Energy Authority, where I was involved as a junior physicist in large-scale projects looking at fundamental physical problems associated with 
Table 1

The previous Fåhraeus medallists

\begin{tabular}{lcc}
\hline Date & Venue & Medallist \\
\hline 1981 & London & Shu Chien \\
1983 & Baden-Baden & John Dormandy \\
1985 & Siena & Holger Schmid-Schönbein \\
1987 & Bordeaux & Jean-Francois Stoltz \\
1989 & Frankfurt & Tullio Di Perri \\
1991 & Southampton & John Stuart \\
1993 & Vienna & Herbert Meiselman \\
1995 & Siena & Albrecht Ehrly \\
1997 & Lisbon & Siegfried Witte \\
2001 & Rouen & Gustav Born \\
2003 & Sofia & Sandro Forconi \\
2005 & Siena & Michel Boisseau \\
\hline
\end{tabular}

nuclear energy. However, the tide was turning away from nuclear energy in the UK. This and the realisation that this was not the sort of physics that I really wanted to be involved in gave me "itchy feet". The result was that I left after 5 years, having been offered a lectureship at St. Mary's Hospital Medical School in London. I stayed there for some 30 extremely happy years until it was merged in 1998 with Imperial College, when I moved back to my alma mater and stayed until I retired in 2005.

St. Mary's was a very fine institution to work at. It was a happy place with a high morale and a very long, renowned and continuing research record of which it was justifiably proud. Its research prowess is illustrated by just two of its famous alumni: Sir Alexander Fleming who discovered the antibiotic effects of penicillin there [1] and Augustus Waller who published the first human ECG while working there in 1887 [2], but there are many more

St. Mary's introduced me to my two great professional loves. As soon as I arrived I started teaching medical students and so discovered the first. In spite of my retirement, I am privileged still to be teaching university students, on a part time basis, and when eventually I am forced to stop it will be with great sadness.

However, as far as this lecture is concerned the more important point is that on joining St. Mary's I was enrolled for a $\mathrm{PhD}$, under the supervision of Professor John Sirs. He was a very stimulating man to work for and I respected him very much. I remember with pleasure the many conversations we had on haemorheology and other things, often over a pint of good English beer. Unfortunately he died a few years ago.

My $\mathrm{PhD}$ project was originally to look at the rate at which cells containing $\mathrm{HbS}$ sickled under differing conditions. This necessitated making a rapid reaction apparatus so that suspensions of $\mathrm{HbS}$ cells could be rapidly mixed with deoxygenating agents and then equally rapidly fixed after a known, but variable, time so that the degree of morphological change in the cell suspension could be measured as a function of time. However, there was a problem in that the supply of blood from sickle cell anaemiacs was more limited than had been anticipated. Consequently, an extra project area was needed to allow me to complete my thesis. John suggested, and I took up the suggestion, that I investigate a novel method he had put forward for measuring red cell deformability [3]. The method is no longer used, but from my point of view it is important because this was my entrée to haemorheology. So I did measure the rate of sickling of HbS-containing cells and I did show the potential, and limitations, of John's method for measuring red cell deformability and so I did get my $\mathrm{PhD}$ [4]. 
After that I dabbled in both haemorheology and in haemostasis, and particularly fibrinogen biochemistry, and was not sure which way to commit myself. Then I discovered that the 2 nd ECCH conference was due to be held in London in 1981 and got myself involved in its organisation. This was a huge success because it allowed me to meet, in the week of the conference, all the major players in the field and many who were going to be important in the years to come. The result was that I became hooked on haemorheology, my second professional love, and from then on I stayed almost exclusively in the field.

Needless to say, in the following years my research group was involved in a variety of haemorheological areas but, like many other groups at the time, we were heavily committed to documenting and explaining the haemorheological disturbances associated with a wide range of clinical conditions, and to investigating whether treatments for these conditions affected any haemorheological abnormalities found.

\section{Smoking studies}

A typical example was the investigation of the effects of smoking tobacco. Like a number of other groups we were able to show that it was detrimental from a haemorheological point of view, and in a dose related manner, i.e. number of cigarettes smoked and length of time that the subject had been smoking. We were also able to show, like others, that stopping the habit had beneficial haemorheological effects in the long run. However what we did that, I think, was unique was look at the very short-term effects of stopping smoking. We were able to do this because there was a large "Smokers Anonymous" clinic at St. Mary's at the time so we had many potential abstainers to work on, they came to the clinic frequently for their "indoctrination" and we were able, as a matter of course, to check they were really not smoking because they had CO analysis of blood samples built into their "therapy". This is important in such studies because smokers are notoriously "economic with the truth" when it comes to talking about their smoking habits to doctors and other professionals. The study showed that the haemorheological response to stopping smoking was very much more rapid than had been previously thought $[5,6]$. This is illustrated in Table 2. It is clear that significant changes in whole blood viscosity and packed cell volume occurred within 2 days and there were similar changes in plasma viscosity, plasma protein concentration and plasma fibrinogen concentration. Furthermore, the changes were lasting and similar for the two sexes. This was important information because of the psychology of smokers. Telling smokers that they will get health benefits from stopping smoking in the long-term, i.e. after many months or years is not very effective - smoking is too addictive - but when they realise that the effects can be beneficial within

\section{Table 2}

The percentage change in haemorheological parameters on the first 4 days after quitting smoking. The data is normalised to $100 \%$ on the day abstention started. There were 12 males and 8 females in the study

\begin{tabular}{|c|c|c|c|c|c|c|}
\hline & & \multicolumn{5}{|c|}{ Days after giving up smoking } \\
\hline & & 0 & 1 & 2 & 3 & 4 \\
\hline \multirow[t]{2}{*}{ High shear rate blood viscosity $\left(128.5 \mathrm{~s}^{-1}\right)$} & $\sigma^{2}$ & 100 & 99 & $94.5^{*}$ & $92^{*}$ & $92^{*}$ \\
\hline & q & 100 & 96 & $92.5^{*}$ & $92^{*}$ & $93^{*}$ \\
\hline \multirow[t]{2}{*}{ Low shear rate blood viscosity $\left(0.277 \mathrm{~s}^{-1}\right)$} & $\sigma^{2}$ & 100 & 95 & $86^{*}$ & $82^{*}$ & $80.5^{*}$ \\
\hline & q & 100 & 93 & $85^{*}$ & $86^{*}$ & $86^{*}$ \\
\hline \multirow[t]{2}{*}{ Haematocrit } & $\sigma^{7}$ & 100 & 98.5 & $95.5^{*}$ & $95^{*}$ & $95^{*}$ \\
\hline & q & 100 & 97 & $95^{*}$ & $95.5^{*}$ & $95.5^{*}$ \\
\hline
\end{tabular}

*Indicates a significant change from baseline [6]. 
a couple of days their response can be expected to be positive. This was the only work that came out of my group that got into the national press in the UK and it was used widely as propaganda to help persuade smokers to quit. However, as satisfying a piece of research as this was it left with me a certain sense of incompleteness which I think is important and I shall return to later in this paper.

\section{Neonatal and foetal studies}

Another, particularly pleasing, area that my group was involved in was the study of haemorheology in the neonate and the foetus. This was important because there is a frequent need for clinical manipulation of the circulation in neonatology, due to problems like rhesus incompatibility and natural twin-twin and foetus-placenta transfusion [7]. Before we started the work we knew that the haematology of the neonate differed from the adult (Table 3), in particular the haematocrit is higher in the neonate while the plasma viscosity and fibrinogen concentrations are lower [8]. Incidentally, the red cell volume is also larger in the neonate [9]. So it was clear that the neonatal haemorheology was likely to differ significantly from that of the adult.

Our studies in this area were not made easy because of the medical ethics current in the UK at the time. In particular, it was not permitted for blood samples to be taken from children of any age purely for scientific investigative purposes. In order to pursue these studies we had to miniaturise our methods, because the only way that we could get blood directly from babies was to use the small drop left over in the collection tubes of samples taken for routine pathology services. Adequate miniaturisation was managed and, hence, we were able to get standard haemorheological data for the neonate, both term and pre-term [10]. Some of the data is summarised in Table 4 . Whole blood viscosity at both high and low shear rates increased with gestational age (from 24 weeks to term). At term the values were similar to those that are average for adults. The increases were due mainly to a small but steady rise in haematocrit over the period. There was also a substantial increase in plasma viscosity over the same period. However, this does not achieve the adult value at term. This lowered plasma viscosity tends to compensate for the higher haematocrits in term neonates so that the final blood viscosities are similar to those of adults. There were further, more subtle effects present, for example the plasma fibrinogen concentration was not only low in the babies but the fibrinogen was also hypersialinated, both tend to reduce rouleaux formation in the babies and so low shear rate viscosity as well. This decreased rouleaux formation was accentuated by the reduced inherent rouleaugenicity of neonatal cells, especially the pre-term.

Table 3

A comparison of haematocrit, plasma viscosity and plasma fibrinogen concentration $(\mathrm{m} \pm \mathrm{sd}(n))$ between male and female adults and term and pre-term neonates [8]

\begin{tabular}{|c|c|c|c|c|}
\hline & \multicolumn{2}{|c|}{ Neonates } & \multicolumn{2}{|c|}{ Adults } \\
\hline & Pre-term & Term & Male & Female \\
\hline \multirow[t]{2}{*}{ Haematocrit* (\%) } & $48.1 \pm 7.9(14)$ & $49.9 \pm 6.4(60)$ & $44.1 \pm 2.5(19)$ & $40.5 \pm 1.9(6)$ \\
\hline & & & \multicolumn{2}{|c|}{ Sexes combined } \\
\hline Plasma viscosity ${ }^{* *}$ (mPa s) & $1.05 \pm 0.07(6)$ & $1.24 \pm 0.13(22)$ & \multicolumn{2}{|c|}{$1.34 \pm 0.08(19)$} \\
\hline Fibrinogen $^{* * *}(\mathrm{~g} / \mathrm{l})$ & $2.73 \pm 0.77(14)$ & $2.87 \pm 0.52(60)$ & \multicolumn{2}{|c|}{$3.25 \pm 0.56(17)$} \\
\hline
\end{tabular}

*All group significantly different $p<0.01$, except pre-term and term.

${ }^{* *}$ All groups significantly different $p<0.01$.

*** Neonate groups not different, but differ from adults $p<0.05$. 
Table 4

A comparison of average values of the major haemorheological parameters of the neonate (term and pre-term) with those of the adult [10]

\begin{tabular}{|c|c|c|c|c|}
\hline & \multicolumn{3}{|c|}{ Neonate } & \multirow{2}{*}{$\begin{array}{l}\text { Adult } \\
\text { @- }\end{array}$} \\
\hline & 24 weeks & 40 weeks & Range at 40 weeks & \\
\hline Low shear rate blood viscosity $\mathrm{mPa} \mathrm{s}\left(0.277 \mathrm{~s}^{-1}\right)$ & 12 & 42 & $4-80$ & $39-48$ \\
\hline High shear rate blood viscosity $\mathrm{mPa} \mathrm{s}\left(128.5 \mathrm{~s}^{-1}\right)$ & 3.6 & 4.8 & $2.6-6.8$ & $4.3-4.7$ \\
\hline \multirow[t]{2}{*}{ Haematocrit (\%) } & 45 & 50 & $30-65$ & $41-45$ \\
\hline & & & & Same for both \\
\hline Plasma viscosity (mPa s) & 0.96 & 1.16 & $0.95-1.30$ & 1.25 \\
\hline
\end{tabular}

Table 5

The average values the major haemorheological parameters of the foetus at 18 and 36 weeks of gestation [11]

\begin{tabular}{lccc}
\hline & 18 weeks & 36 weeks & Range at 36 weeks \\
\hline Low shear rate blood viscosity $\mathrm{mPa} \mathrm{s}\left(0.277 \mathrm{~s}^{-1}\right)$ & 3.5 & 14 & $7-23$ \\
High shear rate blood viscosity mPa s $\left(128.5 \mathrm{~s}^{-1}\right)$ & 2.5 & 3.8 & $2.8-4.7$ \\
Haematocrit (\%) & 32 & 38 & $31-46$ \\
Plasma viscosity (mPa s) & 0.90 & 1.05 & $0.85-1.27$ \\
\hline
\end{tabular}

However, perhaps the most interesting finding was the huge variation between the babies in the haemorheological parameters; this is shown by the range in Table 4. What was especially surprising was the extraordinarily wide variation in whole blood viscosity, due almost entirely to the massive variation in haematocrit, and this in turn being presumably due to varying amounts of placental transfusion to or from the new born during the birth process. It is an indication of the remarkable tolerance of the circulation to haemorheological change (at least in the neonate) that these were all healthy babies requiring no medical intervention (over and above that which was normal at birth) before or after delivery.

In view of the development of in utero sampling and transfusion, it then became necessary to investigate the haemorheology of the foetus in utero at various gestational ages. Some of the data obtained is summarised in Table 5 [11].

The changes with gestational age mirrored those found in the neonate, i.e. a general increase in whole blood viscosity, at both high and low shear rates, in plasma viscosity and in haematocrit. However, the big difference in the healthy foetus was that the values were lower at any gestational age and there was much less spread in the data. The reason for the latter, of course, is that the foetus has not been subjected to the random effects of birth, and the values are lower because of the lack of transfusion with the placenta.

Circulatory problems are common in both the foetus and the neonate due to such phenomena as rhesus incompatibility, transfusional events between the baby and the placenta at birth or between twins where, because of positioning in the womb, one may steal blood from the other etc. Often the alleviation of these conditions requires blood manipulation, e.g. transfusion, haemodilution etc., both ex utero and in utero. Our data was important in helping to establish criteria governing the transfusion of disturbed babies. 


\section{Haemorheology and in vivo haemodynamics}

After completing this work, I felt yet again a sense of dissatisfaction similar to that after completing the smoking study and after others. The cause of the dissatisfaction was this: while we haemorheologists can talk in general terms of what disturbed haemorheology (measured in vitro) should do in vivo, e.g. increased blood viscosity should increase flow resistance, slow flow or lead to an increase in the activity of the heart to compensate etc., we can not quantitate it in any real way. It is complicated, of course, by the fact that we can not really tell, in any particular situation, the degree to which the circulation can compensate for disturbed haemorheology simply by vascular relaxation. It is further complicated by the fact that at the microcirculatory level the haematocrit can be remarkably different from that in the bulk circulation [12], and this illustrates that we still have a very limited view of how our in vitro measurements relate to the in vivo situation. We do know, of course, that where haemorheology is grossly abnormal, e.g. where haematocrit is very high [13] or where plasma viscosity is hugely raised [14], as is common in Waldenstrom's macroglobulinaemia, then serious circulatory disturbance will ensue. The problem is that we do not know the limits; we cannot, in general, quantitate the disturbance to in vivo haemodynamics that an in vitro determined haemorheological abnormality will induce. For example, the degree of haemorheological disturbance seen in some of the neonates referred to above was extreme yet the babies coped without any need for clinical assistance. The point is that our field of research is severely handicapped because of insufficient information relating haemorheological alterations measured in the viscometer and elsewhere in the laboratory to their effects on in vivo haemodynamics.

Groups have been working in this area for many years, the work of Whittaker and Winton [15] is a classic example, then there is the work of Robin Fahraeus himself (e.g. [16]), Herb Lipowsky (e.g. [12, 17]) and more recently Oguz Baskurt (e.g. [18,19]) and, of course, there are others. In spite of their results, our ability to relate in vitro haemorheology to in vivo haemodynamics remains minimal

To take a very specific example, after all the work done over the years on rouleaux formation it is still not clear whether it is a good or bad thing as far as in vivo haemodynamics is concerned [20]. Most haemorheologists seem to assume that, because the intensity of rouleaux formation tends to increase in association with pathology, it must be a bad haemodynamically. However, the evidence is, at most, equivocal. In spite of this, many groups are still producing papers looking at altered rouleaux formation in clinical conditions as if it were of great importance. There are similar difficulties in other areas, e.g. the in vivo significance of naturally occurring changes in red cell deformability and of the influence of elevated low shear rate viscosity of blood (measured in vitro) are similarly obscure.

I believe that this lack is at least in part the cause of the decline in interest in haemorheology in parts of the world where previously it was strong, in particular the UK. In my view this is the area that now needs the major endeavour if haemorheology is to advance in a meaningful way from where it is today. Research groups are needed to work on the relations between haemorheological parameters, measured in the laboratory, and in vivo flow. It is certainly not an easy area of research, but I believe that it is vital to the continuity of our field and that there is nothing more important.

I tried, late in my career, to get funding to allow my group to get into this area, but the granting bodies in the UK were not interested. So as an alternative we started to look at haemorheology in mammals other than humans. We hoped that the differences and similarities in haemorheological parameters between the mammals would give some insight into the questions raised above. 


\section{Mammalian studies}

At the outset we were not sure what to expect; on the one hand one might expect considerable haemorheological variation between the mammals, not least because they vary enormously in size from the elephant and, more, the blue whale at the one end of the spectrum to the pygmy shrew at the other. Furthermore they live in vastly different environments, some are entirely aquatic, some inhabit very arid areas and others live in desperately cold environments. Yet again, they have very different nutritional requirements, living habits etc. On the other hand one might expect considerable haemorheological correspondence because of their remarkable anatomical/physiological similarity: they all breathe air with similar respiratory systems, carry oxygen with similar haemoglobin molecules and have similar circulatory systems.

\subsection{Haematological comparison}

The first interesting comparison here is of erythrocyte parameters (because of their potential haemorheological influences). Table 6 shows the distribution of red blood cell parameters across a large number of different mammalian species collected by Gascoyne and Hawkey [21]. What is striking is the narrowness of the spread of haematocrit, whole blood haemoglobin and, especially, mean cellular haemoglobin concentration. This is presumably saying something important about the respiratory/circulatory similarities between the mammals, in particular that the major haematological criterion is adequate haemoglobin to carry the oxygen needed.

On the other hand the mean cell volume (MCV), red cell count and mean cell haemoglobin are astonishingly variable. The variation in the size of the RBC is colossal as is that of the cell number (both show a 6-fold variation from largest to smallest). It is of interest to note that there is no correlation between MCV and animal size. At first sight this vast range of MCV seems extraordinary. One significant consequence, because of the relative constancy in haematocrit across the mammals, is that those mammals with small RBC's have to produce much more erythrocyte membrane to cover their large number of small cells than mammals which produce a small number of large cells. It might have been anticipated that there would have been an optimum RBC size to allow reasonable access to the microcirculation while being big enough to be deformed in the microcirculation to mix the haemoglobin to facilitate gas exchange. This is obviously not the case. However, a problem in trying to analyse the situation here is the lack of adequate knowledge of comparative mammalian microcirculatory anatomy and haemodynamics. Nevertheless, such data as are available suggest that microcirculatory size is not

Table 6

Comparative mammalian red cell data [21]. The mean, standard deviation and coefficient of variation (CV) are given

\begin{tabular}{lcc}
\hline \multicolumn{2}{l}{ Similarities } \\
\hline Haematocrit & $42.8 \pm 5.8 \%$, CV $14 \%$ \\
Whole blood haemoglobin (WBH) & $14.8 \pm 2.1 \mathrm{~g} / \mathrm{dl}, \mathrm{CV} 14 \%$ \\
Mean cell haemoglobin concentration (MCHC) & $34.6 \pm 3.0 \mathrm{~g} / \mathrm{dl}, \mathrm{CV} 8.5 \%$ \\
& \\
\hline Mean cell volume (MCV) & Differences & $64.4 \pm 23.7 \mathrm{fl}, \mathrm{CV} 37 \% *$ \\
Red cell count (RCC) & $7.6 \pm 2.810^{12} / 1, \mathrm{CV} 37 \%$ \\
Mean cell haemoglobin $(\mathrm{MCH})$ & $22.1 \pm 8.4 \mathrm{pg}, \mathrm{CV} 38 \%$ \\
\hline
\end{tabular}

${ }^{*}$ Goat $\sim 20 \mathrm{fl}$, mouse $\sim 70 \mathrm{fl}$, elephant $\sim 130 \mathrm{fl}$. 
Table 7

A comparison of mammalian haemorheological parameters across 19 different mammalian species [22]

\begin{tabular}{ll}
\hline & \multicolumn{1}{c}{ Range } \\
\hline Plasma viscosity & $1.1 \mathrm{mPa}$ s (rabbit) to $1.6 \mathrm{mPa}$ s (rhinoceros) \\
$\left(37^{\circ} \mathrm{C}\right)$ & (Good correlation with plasma protein concentration) \\
High shear blood viscosity & 2-fold variation: \\
$\left(128.5 \mathrm{~s}^{-1}, 37^{\circ} \mathrm{C}\right)$ & $3.4 \mathrm{mPa}$ s (goat) to $6.0 \mathrm{mPa}$ s (leopard) \\
Low shear blood viscosity & 18-fold variation: \\
$\left(0.277 \mathrm{~s}^{-1}, 37^{\circ} \mathrm{C}\right)$ & $\sim 5 \mathrm{mPa}$ s (sheep, goat, cattle) to $\sim 90 \mathrm{mPa} \mathrm{s}$ (horse, leopard, rhinoceros) \\
\hline
\end{tabular}

vastly different across the mammals and does not correlate with the size of the red cells. But again I return to my hobby horse above, we know too little about the relation of laboratory measurements to in vivo haemodynamics to be able to analyse adequately the situation here. However one feels that hidden within these sorts of comparative studies are important haemorheological/haemodynamic relationships and insights.

\subsection{Haemorheological comparison}

My group did a comparative study of the haemorheological parameters of 19 different mammalian species. A summary of the results is given in Table 7 [22]. The plasma viscosities varied by about $50 \%$ from the lowest, rabbit, to the highest, rhinoceros, and there was a good correlation between plasma viscosity and plasma protein concentration. The high shear rate blood viscosity varied by about 2 -fold from the lowest to the highest (goat to leopard). This variation could be explained almost entirely by the differences in haematocrit between the mammals. Note that there was no correlation between high shear rate viscosity and MCV. Furthermore, even though studies suggest that there are differences in red cell deformability between mammals [23] such differences did not have a noticeable effect on the high shear rate viscosity variation that we found between mammals. The most remarkable item was, however, the low shear rate viscosity data. Here there was an 18 -fold variation across the mammals, and this was due, almost entirely, to huge differences in the level of rouleaux formation between the mammals. At first sight the implication of this is that rouleaux formation is a haemorheological epiphenomenon that makes huge impact when viscosity is measured at low shear rate in the laboratory, but probably hardly matters in vivo. It seems to me that comparative haemodynamic studies on mammals with high and low rouleaux formation ought to be able to prove or disprove the implication and cast real light on the haemodynamic significance of rouleaux formation.

\section{Mechanism of rouleaux formation}

The mechanism of rouleaux formation is still not clear. Aggregant molecules are necessary for it to occur but how they cause it is still not known. The old hypothesis for rouleaux formation, i.e. the crossbridging hypothesis, was never proven but was essentially universally accepted until the arrival of a more recent concept, i.e. the depletion layer hypothesis [24]. The whole area has been further complicated by the discovery of cell-specific factors associated with rouleaux formation in humans. That is to say there is in the general population a spectrum of responders to rouleaugenic molecules, i.e. high responders and low responders and a full range between. Furthermore, the cause is clearly inherent in the structure of the erythrocyte, but its nature is still mysterious. The mammalian studies discussed above showed that there 
were huge differences in rouleaux formation between the mammals, e.g. sheep, goat and cattle show no rouleaux formation at all while horse, leopard and rhinoceros have extremely high levels. Furthermore, these studies [22] showed that the differences were almost entirely due to inherent cellular variation between the erythrocytes of the different species. Other studies have shown that neither RBC size nor deformability are relevant here [23]. This shows that the cell specific factors must lie in the erythrocyte membrane and this was confirmed by studies such as that of Kaibara [25]. He showed that RBC's from cattle and sheep, which do not form rouleaux in plasma or fibrinogen solutions, can be made to form rouleaux if the RBC surface is degraded by trypsin.

The studies of Kaibara stimulated my group to investigate further the effects of enzymatic degradation of red cell surfaces on rouleaux formation. One study compared the effects of different enzymes on electrophoretic mobility and on rouleaux formation (since surface charge is considered to have a potent influence on rouleaux formation [26]). Normal human red cells were degraded by chymotrypsin (specific for hydrophobic aromatic groups, e.g. phenalanine and tyrosine), trypsin (specific for hydrophilic groups e.g. lysine and arginine), bromelain (broad range of activity, e.g. phenylalanine, tyrosine, lysine and arginine) and neuraminidase (specific for sialic acid). The first three were used at a concentration of $5 \mathrm{mg} / \mathrm{ml}$ of cells and neuraminidase at $33 \mathrm{U} / \mathrm{ml}$ of cells, and the reactions allowed to go to completion. The cells were then thoroughly washed and suspended in PBS, at $45 \%$ haematocrit, containing either fibrinogen or dextran. Electrophoretic mobility (EPM) and red cell aggregation were estimated (the latter from low shear rate viscosity). The corresponding data were plotted against one another in Fig. 1. The upper curve is that generated by dextran $70(15 \mathrm{~g} / \mathrm{l})$. This behaved as expected, i.e. as the surface charge was progressively reduced by the enzymes so the aggregability of the cells progressively increased. The fibrinogen $(6 \mathrm{~g} / \mathrm{l})$ data however, shown in the lower curve, is strange; the change in EPM (and surface charge) induced by chymotrypsin seems to have no effect on rouleaux formation and again there is no difference in rouleaux formation between cells digested with bromelain or with neuraminidase in spite of a large differences in EPM. The only conclusion that seems compatible with these data is that the mechanism of rouleaux formation is different between dextran and fibrinogen. It would imply that neither the cross bridging nor the depletion layer hypothesis can be universally, and individually, true for all rouleaugenic molecules.

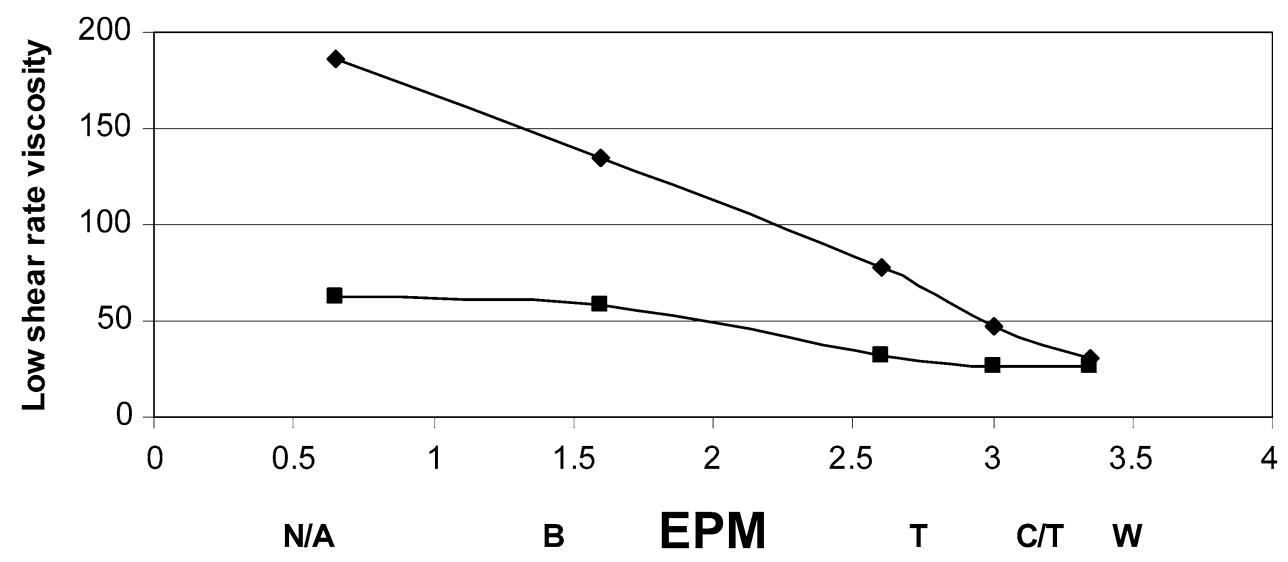

Fig. 1. Comparison of the effects of enzymatic digestion of human erythrocytes on electrophoretic mobility (EPM) and rouleaux formation (estimated from low shear rate viscosity). Upper curve used dextran $70(15 \mathrm{~g} / \mathrm{l})$ as aggregant and the lower curve used fibrinogen $(6 \mathrm{~g} / \mathrm{l})$. The enzymes used were chymotrypsin, $\mathrm{C} / \mathrm{T}$, trypsin, $\mathrm{T}$, bromelain, $\mathrm{B}$, and neuraminidase, N/A. W corresponds to the washed, untreated cell suspension. 
In another study human RBC's were progressively digested with bromelain and then the aggregation induced by four very different aggregants compared [27]. Typical results are shown in Fig. 2. The starting concentrations of the aggregants were designed to give similar degrees of aggregation of the undigested cells. It can be seen that dextran, polyvinylpropylene (PVP) and fibrinogen behaved similarly in that increasing the digestion increased rouleaugenicity of the cells until it reached a plateaux; this was as expected. Heparin, however, behaved bizarrely; as digestion progressed, the rouleaugenicity very rapidly increased to a high maximum and then steadily declined. The conclusion from this has also to be as above that a single mechanism of rouleaux formation is unlikely to be true for all aggregants.

Even more unusual results accrued when other mammals are investigated similarly to the above [27]. Figure 3 shows such data from a similar study of RBCs from the horse (a mammal with very high

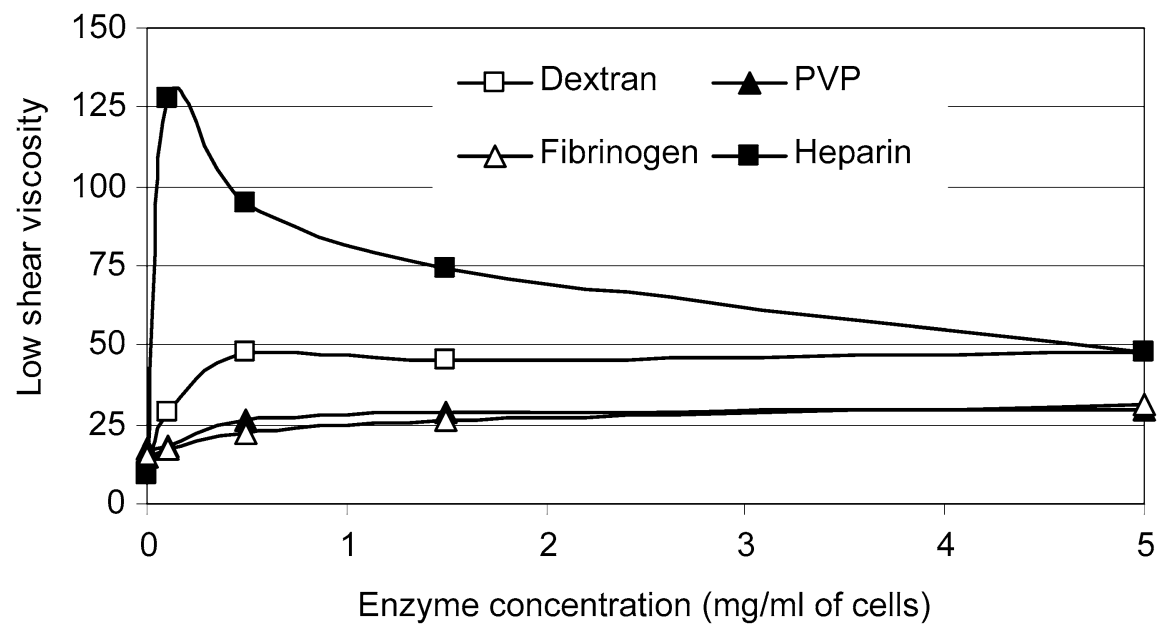

Fig. 2. Effects of progressive bromelain digestion on rouleaugenicity of human RBCs induced by four different aggregants, heparin, dextran 70, polyvinylpropylene (PVP) and fibrinogen.

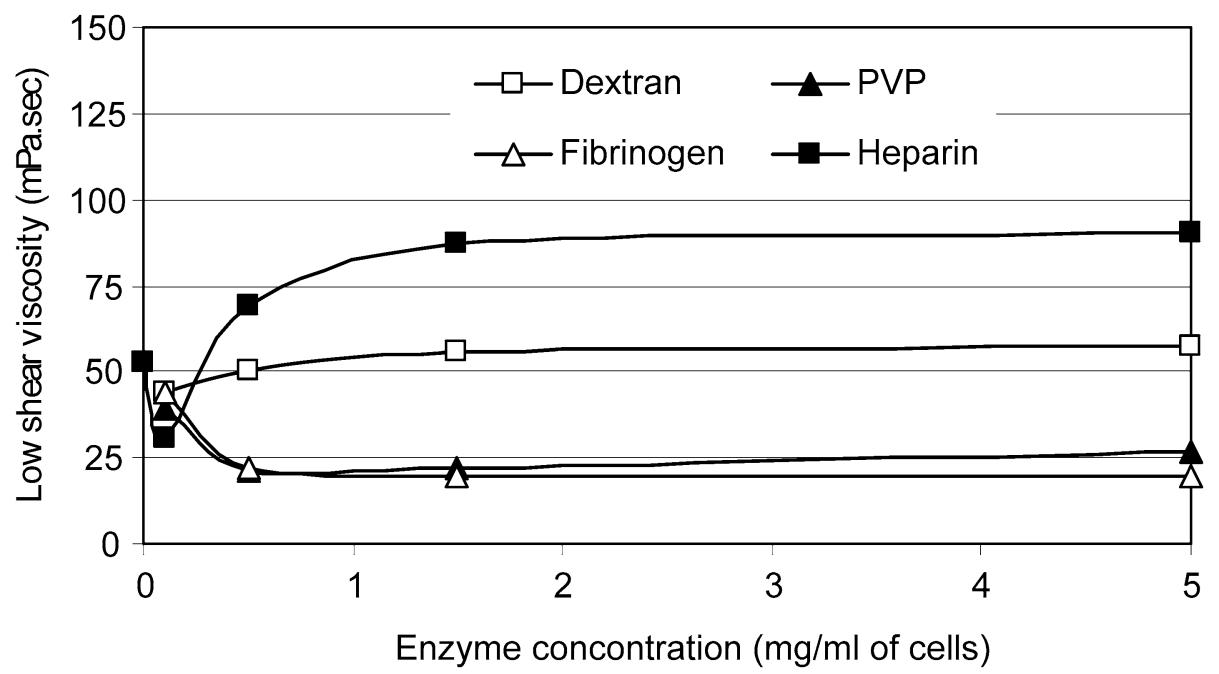

Fig. 3. Effects of progressive bromelain digestion on rouleaugenicity of equine RBCs induced by four different aggregants, heparin, dextran 70, polyvinylpropylene (PVP) and fibrinogen. 
inherent rouleaugenicity in its RBC's). It is clear that the response is very different from the human. The effects of fibrinogen and PVP now both fall to a low steady level as digestion progresses. There is hardly any change to the effect of dextran. However, the effect of heparin first falls then rises to a higher plateau than the start value. I cannot explain the different responses seen here, but I feel sure that implicit in such studies is huge insight into the mechanisms of rouleaux formation.

\section{Conclusion}

In conclusion, I thank everyone who was involved in bestowing the honour of Fåhraeus Medal on me this year and I hope this, probably my last talk to a haemorheological audience, has given something of interest.

\section{References}

[1] A. Fleming, On a remarkable bacteriolytic element found in tissues and secretions, Proc. Roy. Soc. Ser. B 93 (1922), 306-317.

[2] A.D. Waller, A demonstration on man of electromotive changes accompanying the heart's beat, J. Physiol. (London) 8 (1887), 229-234.

[3] J.A. Sirs, Automatic recording of the rate of packing of erythrocytes in blood by a centrifuge, Phys. Med. Biol. 15 (1970), 9-14.

[4] M.W. Rampling, The flexibility of the erythrocyte and the rate of sickling of cells containing haemoglobin $\mathrm{S}, \mathrm{PhD}$ thesis, University of London, 1972.

[5] M.W. Rampling, J.R. Brown, R.J. Robinson, M.D. Feher, S. Cholerton and P.S. Sever, The short-term effects of abstention from tobacco by cigarette smokers on blood viscosity and related parameters, Clin. Hemorheol. 11 (1991), 441-446.

[6] M. Rothwell, M.W. Rampling, S. Cholerton and P. Sever, Haemorheological changes in the very short term after abstention from tobacco by cigarette smokers, Br. J. Haematol. 79 (1991), 500-503.

[7] C.H.M. Walker, Rheology of the newborn and their disorders, in: Clinical Blood Rheology, Vol. II, G.D.O. Lowe, ed., CRC Press, Boca Raton, 1988, pp. 213-232.

[8] M.W. Rampling, P. Whittingstall, G. Martin, S. Bignall, R.P.A. Rivers, T.S. Lissauer and P.C. Bailey, A comparison of the rheological properties of neonatal and adult blood, Pediatr. Res. 25 (1989), 457-460.

[9] F.A. Oski and J.L. Naiman, Hematologic Problems in the Newborn, W.B. Saunders, Philadelphia, 1982, pp. 1-31.

[10] M.A. Anwar, M.W. Rampling, S. Bignall and R.P.A. Rivers, The variation with gestational age of the rheological properties of the blood of the new-born, Br. J. Haematol. 86 (1994), 163-168.

[11] C.R. Welch, M.W. Rampling, M.A. Anwar, D.G. Talbot and C.H. Rodeck, Gestational reference ranges for fetal haemorheological parameters, Clin. Haemorheol. 14 (1994), 93-104.

[12] H.H. Lipowsky, S. Usami and S. Chien, In vivo measurement of apparent viscosity and microvessel hematocrit in the mesentery of the cat, Microvasc. Res. 19 (1980), 297-319.

[13] T.C. Pearson, Rheology of polycythemias, in: Clinical Blood Rheology, Vol. II, G.D.O. Lowe, ed., CRC Press, Boca Raton, 1988, pp. 23-42.

[14] G.D.O. Lowe, Rheology of paraproteinemias and leukemias, in: Clinical Blood Rheology, Vol. II, G.D.O. Lowe, ed., CRC Press, Boca Raton, 1988, pp. 67-88.

[15] S.R.F. Whittaker and F.R. Winton, The apparent viscosity of blood flowing in the isolated hindlimb of the deg, and its variation with corpuscular concentration, J. Physiol. 78 (1933), 239-369.

[16] R. Fåhraeus, The suspension stability of blood, Physiol. Rev. 9(1929), 241-274.

[17] H.H. Lipowsky and J.C. Firrell, Microvascular haemodynamics during systemic haemodilution and haemoconcentration, Am. J. Physiol. 250 (1986), H908-H922.

[18] O. Yalcin, H.J. Meiselman, J.K. Armstrong and O.K. Baskurt, Effect of enhanced red blood cell aggregation on blood flow resistance in an isolated-perfused guinea pig heart preparation, Biorheology 42 (2005) 511-520.

[19] O. Yalcin, F. Aydin, P. Ulker, M. Uyuklu, F. Gungor, J.K. Armstrong, H.J. Meiselman and O.K. Baskurt, Effects of red blood cell aggregation on myocardial haematocrit gradient using two approaches to increase aggregation, Am. J. Physiol. 290 (2006), H765-H771.

[20] H.J. Meiselman and O.K. Baskurt, Hemorheology and hemodynamics; Dove andare?, Clin. Hemorheol. Microcirc. 35 (2006), 37-43. 
[21] S.G. Gascoyne and C. Hawkey, Patterns of variation of vertebrate haematology, Clin. Hemorheol. 12 (1992), 627-637.

[22] H. Johnn, C. Phipps, S. Gascoyne, C. Hawkey and M.W. Rampling, A comparison of the viscometric properties of the blood from a wide range of mammals, Clin. Hemorheol. 12 (1992), 639-647.

[23] R. Plasenzotti, B. Stoiber, M. Posch and U. Windberer, Red blood cell deformability and aggregation behaviour in different animal species, Clin. Hemorheol. Microcirc. 31 (2004), 105-111.

[24] M.W. Rampling, H.J. Meiselman and O.K. Baskurt, Influence of cell-specific factors on red cell aggregation, Biorheology 4 (2004), 91-112.

[25] M. Kaibara, Rheological behaviors of bovine blood forming artificial rouleaux, Biorheology 20 (1983), 583-592.

[26] M.J. Pearson, An investigation into the mechanism of rouleaux formation and the development of improved methods for its quantitation, PhD thesis, London University, 1996.

[27] M.W. Rampling and O. Warren, A comparison of the effects of bromelain digestion on the aggregation of human, equine and bovine red cells, Biorheology 36 (1999), 168. 